\title{
TP53 codon 72 polymorphism is associated with pancreatic cancer risk in males, smokers and drinkers
}

\author{
TAKAYUKI SONOYAMA ${ }^{1}$, AKIKO SAKAI ${ }^{2}$, YUICHIRO MITA ${ }^{2}$, YUKIKO YASUDA $^{2}$, \\ HIROFUMI KAWAMOTO ${ }^{1}$, TAKAHITO YAGI ${ }^{3}$, MASAO YOSHIOKA ${ }^{4}$, TETSUSHIGE MIMURA ${ }^{4}$, \\ KEI NAKACHI ${ }^{5}$, MAMORU OUCHIDA ${ }^{2}$, KAZUHIDE YAMAMOTO ${ }^{1}$ and KENJI SHIMIZU ${ }^{2}$
}

\begin{abstract}
Departments of ${ }^{1}$ Gastroenterology and Hepatology, ${ }^{2}$ Molecular Genetics, and ${ }^{3}$ Gastroenterological Surgery, Transplant and Surgical Oncology, Graduate School of Medicine, Dentistry and Pharmaceutical Science, Okayama University, Okayama 700-8558; ${ }^{4}$ Okayama Saiseikai Hospital, Okayama 700-8511; ${ }^{5}$ Department of Radiobiology/ Molecular Epidemiology, Radiation Effects Research Foundation, Hiroshima 732-0815, Japan
\end{abstract}

Received October 11, 2010; Accepted February 16, 2011

DOI: $10.3892 / \mathrm{mmr} .2011 .449$

\begin{abstract}
Tumor protein p53 (TP53) is the best-known tumor suppressor gene and plays a crucial role in carcinogenesis. The TP53 Arg 72 Pro polymorphism has been reported to be a risk factor for several types of cancer, but its association with pancreatic cancer has not been fully evaluated. Therefore, we investigated the effects of this polymorphism on pancreatic cancer in relation to smoking and drinking habits by examining the distribution of the SNP genotypes in 226 pancreatic cancer patients and 448 healthy controls. The frequencies of Arg/Arg, Arg/Pro and Pro/Pro were found to be 37, 49 and $15 \%$ in the pancreatic cancer cases and 44, 46 and $10 \%$ in the controls, respectively. Compared to the controls with the Arg/Arg genotype, cases with Pro/Pro homozygosity exhibited a significantly increased risk [adjusted odds ratio $(\mathrm{OR})=1.70 ; 95 \%$ confidence interval (CI) 1.01-2.88]. In stratified studies, the association was particularly strong in males $(\mathrm{OR}=2.62$; $95 \%$ CI 1.32 5.23), particularly in those smoking in excess of 20 pack-years and drinking in excess of $23 \mathrm{~g}$ ethanol/day (OR=5.02; 95\% CI 1.12-22.51). We found that the TP53 Pro/Pro genotype compared to the Arg/Arg genotype had a profound effect on pancreatic cancer risk among males, particularly among heavy smokers and excessive alcohol drinkers.
\end{abstract}

\section{Introduction}

Pancreatic cancer is a leading cause of cancer-related death, ranking fifth in Japan (1), fourth in the US (2) and fifth in

Correspondence to: Dr Takayuki Sonoyama, Department of Gastroenterology and Hepatology, Graduate School of Medicine, Dentistry and Pharmaceutical Science, Okayama University, Shikata-cho 2-5-1, Kita-ku, Okayama 700-8558, Japan

E-mail: gmd13601@s.okayama-u.ac.jp

Key words: tumor protein p53, pancreas, cancer, single-nucleotide polymorphism, polymorphism
Europe (3). The number of pancreatic cancer patients is gradually increasing as the population ages (1). Although newly-developed anti-cancer drugs such as gemcitabine and molecular-targeted agents have been used for treatment (4), the 5-year relative survival rate remains below 5-7\% $(1,2)$. Pancreatic cancer has a dismal prognosis, in part because only $15-20 \%$ of patients have resectable disease at the time of diagnosis (5). This means that in most patients with pancreatic cancer, the disease is diagnosed at too late a stage to be appropriately treated, eliminating their chances of survival. For early detection strategy, various predisposing factors to pancreatic cancer have been reported, including age $(6,7)$, gender $(8,9)$, smoking $(10,11)$, obesity $(12,13)$, diabetes mellitus $(14,15)$, diet $(16,17)$ (a high intake of fried food has been associated with increased risk and a high intake of folate from food sources, such as vegetables and fruits, with reduced risk), pancreatitis $(18,19)$, inherited genetic factors such as hereditary breast and ovarian cancer syndrome, familial atypical multiple mole melanoma, Peutz-Jeghers syndrome, ataxia-telangiectasia and hereditary non-polyposis colorectal cancer $(20,21)$. At present, however, there is no established method to narrow down a high-risk group in the general population.

In recent years, single-nucleotide polymorphisms (SNPs) have received much attention as candidates for new diagnostic biomarkers. Associations between pancreatic cancer risk and SNPs in particular genes have been reported, such as the UDP-glucuronosyltransferase (22), N-acetyltransferase 1 (23), $\mathrm{X}$-ray repair cross-complementing group 1 (XRCC1) (24), group 2 (XRCC2) and group 3 (XRCC3) (25), 5,10-methylenetetrahydrofolate reductase $(26,27)$, methionine synthase reductase (28) and cyclooxygenase-2 (29). Tumor protein p53 (TP53) is the best-known tumor suppressor gene and plays a crucial role in carcinogenesis. The polymorphism Arg 72 Pro has been reported to be a risk factor for various types of cancer, including pancreatic cancer, among numerous ethnicities (30-38). To our knowledge, this is the first report showing that a polymorphic variant of the TP53 codon 72 is associated with pancreatic cancer susceptibility in a subset of the Japanese population. 


\section{Materials and methods}

Subjects. The case group comprised 226 patients with pancreatic cancer (132 men, 94 women; mean age $65.0 \pm 10.0$ years). The cases were treated at Okayama University Hospital or Okayama Saiseikai Hospital (Okayama, Japan). Pancreatic cancer was diagnosed histopathologically by endoscopic retrograde cholangiopancreatography and/or endoscopic ultrasound-guided fine needle aspiration, resected specimen or other modalities. Clinical and histopathological classification of the tumors were made according to the criteria of the UICC Tumor-Node-Metastasis Classification of Malignant Tumors (TNM), 6th edition, 2002. The hospitals accept patients from Okayama and other prefectures in Japan. Controls were from two sources: 202 healthy individuals recruited from a cohort study in a Japanese general population older than 40 years of age in a town near Saitama Cancer Center (39), and 246 healthy individuals from Kusaka Hospital in Okayama. All cases and controls were Japanese. The age, gender, personal medical history, family history of disease, and smoking and drinking habits of the subjects were obtained via questionnaires and medical records from Kusaka Hospital, Okayama Saiseikai Hospital and Okayama University Hospital. Written informed consent was obtained from all pancreatic cancer cases and healthy controls. The study was approved by the Bioethics Committee of Okayama University Medical School.

DNA isolation and genotyping. The genomic DNA of the 226 cases and 446 healthy controls was extracted from peripheral lymphocytes using sodium dodecyl sulfate/proteinase K treatment, phenol-chloroform extraction and ethanol precipitation. Genotyping of the TP53 Arg 72 Pro polymorphism was carried out by the SNaPshot method (Applied Biosystems, Foster City, CA, USA). Genomic DNA (50 ng/ $\mu \mathrm{l})$ was first amplified using Taq DNA polymerase (Takara, Shiga, Japan) and a primer set (sense 5'-GACTGCTCTTTTCACCCATCTA; anti-sense 5'-TGCAGGGGGATACGGCCAG). Polymerase chain reaction (PCR) parameters were: $94^{\circ} \mathrm{C}$ for $3 \mathrm{~min}$, followed by 32 cycles at $94^{\circ} \mathrm{C}$ for $30 \mathrm{sec}, 60^{\circ} \mathrm{C}$ for $30 \mathrm{sec}$ and $70^{\circ} \mathrm{C}$ for $30 \mathrm{sec}$, and a final extension step at $72^{\circ} \mathrm{C}$ for $7 \mathrm{~min}$. After amplification, the PCR products were purified by ExoSAP (exonuclease I and shrimp alkaline phosphatase) at $37^{\circ} \mathrm{C}$ for $90 \mathrm{~min}$ and $75^{\circ} \mathrm{C}$ for $15 \mathrm{~min}$. After the treatment, the PCR product was amplified by SNaPshot Ready Reation Mix and typing primer (5'-TTTTTTTTTTTTTTTTTTTTTTTTTTT TTTTTTTTCCCAGAATGCCAGAGGCTGCTCCCC). The genotype was determined by the ABI3100 sequencer (Applied Biosystems) after purification by SAP and analyzed by GeneMapper 3.0 software (Applied Biosystems).

Statistical analysis. The allele frequencies of the polymorphism TP53 were compared between pancreatic cancer cases and healthy controls. The distribution of the genotype (Arg/ Arg, Arg/Pro, Pro/Pro) was tested for adherence to HardyWeinberg equilibrium in all of the cases and the controls. The Chi-square test was used to compare the genotype distribution between the cases and controls. One-way ANOVA was used to evaluate the association between age of onset and the TP53 polymorphism. Odds ratios (ORs) and 95\% confidence intervals (95\% CIs) were used to estimate the risk associated
Table I. Characteristics of cases and controls.

\begin{tabular}{lrrr}
\hline & Cases (\%) & Controls (\%) & P-value $^{\text {a }}$ \\
\hline Total no. & 226 & 448 & \\
Age & & & 0.029 \\
$\leq 50$ & $13(6)$ & $33(7)$ & \\
$51-60$ & $49(22)$ & $58(13)$ & \\
$61-70$ & $78(34)$ & $177(40)$ & \\
$>70$ & $86(38)$ & $180(40)$ & \\
Gender & & & 0.179 \\
Male & $132(58)$ & $286(64)$ & \\
Female & $94(42)$ & $162(36)$ & \\
Smoking history & & & 0.934 \\
$\quad$ Non-smoker & $109(48)$ & $219(49)$ & \\
Smoker & $115(51)$ & $225(50)$ & \\
$\quad$ Unknown & $2(1)$ & $4(1)$ & \\
Drinking history & & & 0.172 \\
$\quad$ Non-drinker & $135(60)$ & $295(66)$ & \\
Drinker & $89(39)$ & $153(34)$ & \\
Unknown & $2(1)$ & $0(0)$ & \\
\hline
\end{tabular}

${ }^{a}$ Analyzed by the Chi-square test after excluding unknowns.

with the genotype. The OR and 95\% CI were adjusted for age, gender, and history of smoking and drinking by an unconditional logistic regression model using SPSS software ver. 12.0 (SPSS Inc., Tokyo, Japan).

\section{Results}

The characteristics of the 226 pancreatic cancer cases and 446 healthy controls are shown in Table I. There were no significant differences in terms of gender or smoking and drinking habits between the two groups, but there was a difference in age distribution $(\mathrm{P}=0.029)$.

The frequencies of the genotypes and alleles in the TP53 gene are shown in Table II. The frequencies of Arg/Arg, Arg/ Pro and Pro/Pro were found to be 37, 49 and $15 \%$ in the pancreatic cancer cases, and 44, 46 and $10 \%$ in the controls, respectively. All of the results were in Hardy-Weinberg equilibrium. Compared to the controls with the Arg/Arg genotype, cases with Pro/Pro homozygosity exhibited an increased risk with statistical significance (adjusted OR $=1.70 ; 95 \% \mathrm{CI}$ 1.01-2.88).

Next, we examined the association between the TP53 Arg 72 Pro genotypes and the risk of pancreatic cancer in relation to gender and history of smoking and drinking (Table III). The adjusted OR of the pancreatic cancer cases in males and in smokers with Pro/Pro was 2.62 (95\% CI 1.32-5.23) and 2.46 (95\% CI 1.18-5.15), respectively. In drinkers, the same genotype exhibited a marginal risk (OR=2.56; 95\% CI 0.99-6.54), whereas there were no significant associations between the TP53 Arg 72 Pro genotypes and the risk of pancreatic cancer among females, non-smokers and non-drinkers. As shown in Table IV, smokers and drinkers were stratified according to the amount of smoking and drinking. A light smoker was defined as smoking $<20$ pack-years and a heavy smoker as $\geq 20$ pack- 
Table II. The TP53 genotype in cases and controls.

TP53 Arg 72 Pro

\begin{tabular}{|c|c|c|}
\hline Cases $(\%)$ & Controls (\%) & P-value ${ }^{a}$ \\
\hline
\end{tabular}

\begin{tabular}{|c|c|c|c|c|}
\hline \multicolumn{5}{|l|}{ Genotype } \\
\hline Arg/Arg & $83(37)$ & $197(44)$ & & 1.00 (reference) \\
\hline Arg/Pro & $110(49)$ & $205(46)$ & $0.161^{\mathrm{c}}$ & $1.29(0.90-1.83)$ \\
\hline Pro/Pro & $33(15)$ & $46(10)$ & $0.047^{\mathrm{c}}$ & $1.70(1.01-2.88)$ \\
\hline \multicolumn{5}{|c|}{ Allele frequencies } \\
\hline Arg & $276(61)$ & $599(67)$ & 0.039 & \\
\hline Pro & $176(39)$ & 297 (33) & & \\
\hline
\end{tabular}

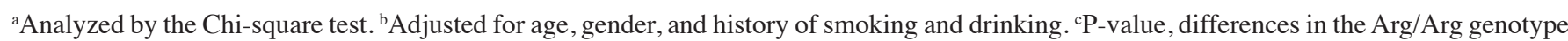
between cases and controls.

Table III. Interaction between the TP53 genotype and gender, smoking and drinking habits.

\begin{tabular}{|c|c|c|c|c|}
\hline & \multicolumn{4}{|c|}{ TP53 Arg 72 Pro } \\
\hline & Genotype & Cases $(\%)$ & Controls (\%) & $\mathrm{OR}^{\mathrm{a}}(95 \% \mathrm{CI})$ \\
\hline \multirow[t]{3}{*}{ Male } & Arg/Arg & $44(33)$ & $125(44)$ & 1.00 (reference) \\
\hline & Arg/Pro & $65(49)$ & $136(48)$ & $1.45(0.91-2.31)$ \\
\hline & Pro/Pro & $23(19)$ & $25 \quad(9)$ & $2.62(1.32-5.23)^{b}$ \\
\hline \multirow[t]{3}{*}{ Female } & Arg/Arg & $38(40)$ & $72(44)$ & 1.00 (reference) \\
\hline & Arg/Pro & $45(48)$ & $69(43)$ & $1.17(0.68-2.02)$ \\
\hline & Pro/Pro & $11(12)$ & $21(13)$ & $0.85(0.36-2.00)$ \\
\hline \multirow[t]{3}{*}{ Smoker } & Arg/Arg & $38(33)$ & $103(46)$ & 1.00 (reference) \\
\hline & Arg/Pro & $58(50)$ & $100(44)$ & $1.67(1.01-2.77)^{\mathrm{b}}$ \\
\hline & Pro/Pro & $19(17)$ & $22(10)$ & $2.46(1.18-5.15)^{b}$ \\
\hline \multirow[t]{3}{*}{ Non-smoker } & Arg/Arg & $44(40)$ & $91(41)$ & 1.00 (reference) \\
\hline & Arg/Pro & $52(48)$ & $104(48)$ & $1.11(0.66-1.83)$ \\
\hline & Pro/Pro & $13(12)$ & $24(11)$ & $1.14(0.53-2.47)$ \\
\hline \multirow[t]{3}{*}{ Drinker } & Arg/Arg & $28(31)$ & $63(41)$ & 1.00 (reference) \\
\hline & Arg/Pro & $48(54)$ & $79(52)$ & $1.68(0.92-3.06)$ \\
\hline & Pro/Pro & $13(15)$ & $11 \quad(7)$ & $2.56(0.99-6.54)$ \\
\hline \multirow[t]{3}{*}{ Non-drinker } & Arg/Arg & $54(40)$ & $134(45)$ & 1.00 (reference) \\
\hline & Arg/Pro & $62(46)$ & $126(43)$ & $1.22(0.78-1.90)$ \\
\hline & Pro/Pro & $19(14)$ & $35(12)$ & $1.38(0.72-2.64)$ \\
\hline
\end{tabular}

aAdjusted for age, gender, and history of smoking and drinking. ${ }^{\mathrm{b}} \mathrm{P}<0.05$, calculated by the Chi-square test.

years, while a moderate drinker was defined as drinking $<23 \mathrm{~g}$ ethanol/day and an excessive drinker as $\geq 23 \mathrm{~g}$ ethanol day. Twenty-three grams ethanol is nearly equal to one cup of Japanese sake. It was not possible to obtain the smoking status for 3 of the 226 cases and 7 of the 448 controls, or the drinking status for 8 of the 226 cases and 5 of the 448 controls. The results showed statistically significant associations between pancreatic cancer risk and heavy smoking $(\mathrm{OR}=2.46 ; 95 \% \mathrm{CI}$ 1.01-6.02), as well as excessive drinking (OR=3.66; $95 \% \mathrm{CI}$ 1.07-12.56).

The potential association of the TP53 Arg 72 Pro genotypes was further investigated with a focus on smoking and alcohol consumption in males and females (Table V). There was no significant association among males without a history of smoking and drinking, while there was a strong association between Pro/Pro homozigosity compared to the reference Arg/ Arg genotype $(\mathrm{OR}=5.02 ; 95 \% \mathrm{CI} 1.12-22.51)$ in males with a history of smoking and/or drinking, particularly heavy smoking ( $\geq 20$ pack-years) and excessive drinking ( $\geq 23 \mathrm{~g}$ ethanol/day. There were no significant differences among females with or without a history of smoking and/or drinking.

To evaluate the association between age of onset and the TP53 polymorphism, each TP53 variant was tested by one-way ANOVA. The results were not statistically significant 
Table IV. Effect of tobacco and alcohol consumption in cases with the TP53 genotype compared to controls.

\begin{tabular}{|c|c|c|c|c|}
\hline & \multicolumn{4}{|c|}{ TP53 Arg72 Pro } \\
\hline & Genotype & Cases (\%) & Controls (\%) & $\mathrm{OR}^{\mathrm{a}}(95 \% \mathrm{CI})$ \\
\hline \multirow{3}{*}{ Non-smoker } & Arg/Arg & $44(40)$ & $91(41)$ & 1.00 (reference) \\
\hline & Arg/Pro & $52(48)$ & $104(48)$ & $1.11(0.67-1.85)$ \\
\hline & Pro/Pro & $13(12)$ & $24(11)$ & $1.14(0.53-2.47)$ \\
\hline \multirow{3}{*}{$\begin{array}{l}\text { Light smoker } \\
(0-20 \text { pack-years) }\end{array}$} & Arg/Arg & $6(39)$ & $25(43)$ & 1.00 (reference) \\
\hline & Arg/Pro & $9(47)$ & $16(45)$ & $2.36(0.68-8.15)$ \\
\hline & Pro/Pro & $5(14)$ & $8(12)$ & $2.61(0.60-11.33)$ \\
\hline \multirow{3}{*}{$\begin{array}{l}\text { Heavy smoker } \\
(\geq 20 \text { pack-years) }\end{array}$} & Arg/Arg & $32(34)$ & $75(43)$ & 1.00 (reference) \\
\hline & Arg/Pro & $48(51)$ & $84(49)$ & $1.43(0.81-2.52)$ \\
\hline & Pro/Pro & $14(15)$ & $14 \quad(8)$ & $2.46(1.01-6.02)^{\mathrm{b}}$ \\
\hline Unknown & & 3 & 7 & \\
\hline \multirow[t]{3}{*}{ Non-drinker } & Arg/Arg & $54(40)$ & $134(45)$ & 1.00 (reference) \\
\hline & Arg/Pro & $62(46)$ & $126(43)$ & $1.24(0.80-1.94)$ \\
\hline & Pro/Pro & 19 (14) & $35(12)$ & $1.38(0.72-2.65)$ \\
\hline \multirow{3}{*}{$\begin{array}{l}\text { Moderate drinker } \\
(0-23 \text { g ethanol/day) }\end{array}$} & Arg/Arg & $9(38)$ & $17(44)$ & 1.00 (reference) \\
\hline & Arg/Pro & $19(49)$ & $25(45)$ & $1.83(0.61-5.48)$ \\
\hline & Pro/Pro & $4(14)$ & $4(11)$ & $1.60(0.30-8.48)$ \\
\hline \multirow{3}{*}{$\begin{array}{l}\text { Excessive drinker } \\
(\geq 23 \mathrm{~g} \text { ethanol/day) }\end{array}$} & Arg/Arg & $17(33)$ & $46(45)$ & 1.00 (reference) \\
\hline & Arg/Pro & $26(51)$ & $50(49)$ & $1.66(0.78-3.55)$ \\
\hline & Pro/Pro & $8(16)$ & $6(6)$ & $3.66(1.07-12.56)^{b}$ \\
\hline Unknown & & 8 & 5 & \\
\hline
\end{tabular}

${ }^{a}$ Adjusted for age, gender, and history of smoking and drinking. ${ }^{\mathrm{b}} \mathrm{P}<0.05$, calculated by the Chi-square test.

$(\mathrm{P}=0.19)$. However, when the subjects were divided into two groups ( $<65$ years and $\geq 65$ years), the Pro/Pro polymorphism was found to be associated with the $\geq 65$ years group $(\mathrm{OR}=2.00$; 95\% CI 1.03-3.90) (Table VI). There was no significant association between the TP53 Arg 72 Pro genotypes and the clinical characteristics of the pancreatic cancer patients (data not shown).

\section{Discussion}

The TP53 gene contributes to a variety of cellular processes, including stress response, DNA repair, apoptosis, cell cycle control and gene expression (40). The codon 72 polymorphism causes an amino-acid substitution of arginine to proline and is located within a proline-rich region of p53. Functional analyses have suggested that codon 72 polymorphic variants of p53 have different effects on the cell cycle and apoptosis (41-43). The TP53 Arg 72 Pro polymorphism has been reported to be associated with the risk of various types of cancer, but to our knowledge has not been fully examined in pancreatic cancer. Thus, the TP53 codon 72 polymorphism was selected as the target of our investigation.

As demonstrated in numerous epidemiologic studies, smoking is a risk factor for pancreatic cancer (44). However, the effect of alcohol is controversial (45). Increased alcohol consumption has been found to linearly elevate the risk of cancer (46). To moderate the amount of alcohol consumed by the Japanese, limits on daily ethanol intake have been recommended by the Ministry of Health, Labor and Welfare (20 g ethanol/day; Healthy Japan 21, a national health care movement) and by 'Development and Evaluation of Cancer Prevention Strategies in Japan' (23 g ethanol/day). The recommended daily maximum amount of alcohol is nearly equivalent to one cup of Japanese sake (23 g ethanol). We defined subjects who drink less than one cup of Japanese sake per day as moderate drinkers and those that consume one cup or more per day as excessive drinkers. The data showed that Pro/Pro homozygosity is a risk factor for pancreatic cancer compared to Arg/Arg homozygosity among smokers and drinkers, in particular heavy smokers and excessive drinkers. Alcohol is not a direct risk factor for pancreatic cancer, but is metabolized to acetaldehyde, a carcinogenic agent. Approximately half of the Japanese individuals were found to have a deficient phenotype for aldehyde dehydrogenase-2 (ALDH2), a key enzyme in the conversion of acetaldehyde to acetate (46). This suggests that the metabolic production of alcohol affects pancreatic cancer risk among Japanese drinkers.

In addition, the data showed that the TP53 Arg 72 Pro polymorphism was strongly associated with male patients who were heavy smokers and excessive drinkers, with stratification according to the amount of smoking and drinking. However, since Pro/Pro homozygosity had a low frequency in the controls $(3 \%)$, it cannot be excluded that the association was spurious. Nevertheless, when we evaluated the genotype 
Table V. Combined effects of tobacco and alcohol consumption in cases with the TP53 genotype compared to controls..

\begin{tabular}{|c|c|c|c|c|}
\hline & \multicolumn{4}{|c|}{ TP53 Arg 72 Pro } \\
\hline & Genotype & Cases (\%) & Controls (\%) & $\mathrm{OR}^{\mathrm{a}}(95 \% \mathrm{CI})$ \\
\hline $\begin{array}{l}\text { Male without } \\
\text { smoking and drinking }\end{array}$ & $\begin{array}{l}\text { Arg/Arg } \\
\text { Arg/Pro } \\
\text { Pro/Pro }\end{array}$ & $\begin{array}{l}9(60) \\
3(20) \\
3(20)\end{array}$ & $\begin{array}{r}20(48) \\
18(43) \\
4(10)\end{array}$ & $\begin{array}{r}1.00 \text { (reference) } \\
0.63(0.15-2.55) \\
1.93(0.33-11.17)\end{array}$ \\
\hline $\begin{array}{l}\text { Male with smoking } \\
(<20 \text { pack-years }) \text { and/or } \\
\text { drinking ( }<23 \mathrm{~g} \text { ethanol/day) }\end{array}$ & $\begin{array}{l}\text { Arg/Arg } \\
\text { Arg/Pro } \\
\text { Pro/Pro }\end{array}$ & $\begin{array}{l}18(27) \\
37(55) \\
12(18)\end{array}$ & $\begin{array}{l}72(40) \\
89(50) \\
17(10)\end{array}$ & $\begin{array}{l}1.00(\text { reference }) \\
1.83(0.94-3.54) \\
2.91(1.16-7.33)^{\mathrm{b}}\end{array}$ \\
\hline $\begin{array}{l}\text { Male with smoking } \\
(\geq 20 \text { pack-years) and } \\
\text { drinking ( } \geq 23 \mathrm{~g} \text { ethanol/day) }\end{array}$ & $\begin{array}{l}\text { Arg/Arg } \\
\text { Arg/Pro } \\
\text { Pro/Pro }\end{array}$ & $\begin{array}{r}14(32) \\
23(52) \\
7(16)\end{array}$ & $\begin{array}{r}31(51) \\
27(44) \\
3 \quad(5)\end{array}$ & $\begin{array}{r}1.00(\text { reference }) \\
1.91(0.82-4.46) \\
5.02(1.12-22.51)^{\mathrm{b}}\end{array}$ \\
\hline $\begin{array}{l}\text { Female without } \\
\text { smoking and drinking }\end{array}$ & $\begin{array}{l}\text { Arg/Arg } \\
\text { Arg/Pro } \\
\text { Pro/Pro }\end{array}$ & $\begin{array}{r}32(40) \\
40(50) \\
8(10)\end{array}$ & $\begin{array}{l}60(45) \\
53(40) \\
19(14)\end{array}$ & $\begin{array}{l}1.00 \text { (reference) } \\
1.42(0.78-2.57) \\
0.78(0.31-2.00)\end{array}$ \\
\hline $\begin{array}{l}\text { Female with smoking } \\
\text { and/or drinking }\end{array}$ & $\begin{array}{l}\text { Arg/Arg } \\
\text { Arg/Pro } \\
\text { Pro/Pro }\end{array}$ & $\begin{array}{l}7(50) \\
5(36) \\
2(14)\end{array}$ & $\begin{array}{r}11(38) \\
16(55) \\
2 \quad(7)\end{array}$ & $\begin{array}{r}1.00 \text { (reference) } \\
0.48(0.10-2.36) \\
1.46(0.15-13.84)\end{array}$ \\
\hline
\end{tabular}

${ }^{\mathrm{a}}$ Adjusted for age, gender, and history of smoking and drinking. ${ }^{\mathrm{b}} \mathrm{P}<0.05$, calculated by the Chi-square test. Some numbers may not amount to the total due to missing data.

TableVI. Association between the TP53 genotype and age distribution, age at diagnosis.

\begin{tabular}{|c|c|c|c|c|c|c|c|}
\hline & \multicolumn{4}{|c|}{ Genotype $n,(\%)$} & \multicolumn{2}{|c|}{ OR $(95 \% \mathrm{CI})^{\mathrm{a}}$} & \multirow[t]{2}{*}{ P-value ${ }^{b}$} \\
\hline & Arg/Arg & Arg/Pro & Pro/Pro & Total & Arg/Pro & Pro/Pro & \\
\hline \multicolumn{8}{|l|}{ Age (<65 years) } \\
\hline Cases & $36(38)$ & $48(50)$ & $12(13)$ & 96 & $1.61(0.91-2.85)$ & $1.29(0.54-3.10)$ & \\
\hline Controls & $68(49)$ & $56(40)$ & $16(11)$ & 140 & & & \\
\hline \multicolumn{8}{|l|}{ Age ( $\geq 65$ years) } \\
\hline Cases & $47(36)$ & $62(48)$ & $21(17)$ & 130 & $1.17(0.74-1.85)$ & $2.00(1.03-3.90)$ & \\
\hline Controls & $129(42)$ & $149(48)$ & $30(10)$ & 308 & & & \\
\hline \multicolumn{8}{|l|}{ Age at diagnosis } \\
\hline Cases & $83(37)$ & $110(49)$ & $33(15)$ & 226 & & & \\
\hline Mean \pm SD $($ years $)$ & $65.5 \pm 10.9$ & $65.8 \pm 9.33$ & $67.8 \pm 10.7$ & & & & 0.19 \\
\hline
\end{tabular}

${ }^{\mathrm{a} A d j u s t e d ~ f o r ~ a g e, ~ g e n d e r, ~ a n d ~ h i s t o r y ~ o f ~ s m o k i n g ~ a n d ~ d r i n k i n g . ~}{ }^{\mathrm{b}}$ Calculated by one-way ANOVA.

among males with a history of smoking and/or drinking, there was still a strong association between the genotype and pancreatic cancer risk $(\mathrm{OR}=2.93$; 95\% CI 1.38-6.26; data not shown). The combination of smoking and drinking is known to be associated with an increased risk of cancer (46). A high prevalence of K-ras mutations in drinkers and smokers with pancreatic cancer has been reported (47). The combination of smoking and drinking may be associated with TP53 Pro/Pro homozygosity, and may act additively to contribute to the risk of pancreatic cancer.

Many SNPs have been reported to be gender-specific (48), but there is no explanation for why the TP53 Arg 72 Pro polymorphism is associated only with males. Thus, being male may itself be a risk factor for pancreatic cancer. The association of TP53 Arg 72 Pro with pancreatic cancer risk in males may be involved in gender-specific pancreatic cancer onset, which may partially reflect specific causes, such as hormone and environmental factors.

Several lines of data have shown that the Pro/Pro genotype is associated with an earlier age of onset in various types of cancer (49-51). The data showed no association between age at diagnosis and TP53 genotypes as a whole. However, when subjects were stratified according to age distribution (divided into two age groups, $<65$ years and $\geq 65$ years), there was a significant difference among the $\geq 65$ years group in terms of the proportion of patients with the Pro/Pro genotype compared 
to the $\mathrm{Arg} / \mathrm{Arg}$ genotype (OR=2.00; 95\% CI 1.03-3.90). Apoptosis, cell cycle arrest and cellular senescence are triggered by activated $\mathrm{p} 53$. These mechanisms are all beneficial for younger subjects, while such effects probably reduce longevity and augment cancer risk in elderly subjects (52). The Pro allele is associated with reduced apoptotic potential $(42,43)$. Low apoptotic activity may favor cancer development due to the failure to eliminate cellular clones carrying DNA damage and a propensity for inflammation, but may also protect against malignancy due to the preservation of antitumor immune cells (40). In other words, reduced apoptotic Pro allele may favor the renewal and maintenance of fragile tissues in older individuals. Thus, there is potentially conflicting evidence that the Pro allele leads to longevity, whereas it also increases cancer risk. As for the incidence of pancreatic cancer, longstanding accumulated damage due to tobacco, alcohol, ultraviolet light exposure and diet may at a certain age affect pancreatic cancer risk in elderly individuals with the TP53 72 Pro polymorphism. Our results suggest that this genotype is not associated with the early onset of pancreatic cancer, but is related to its incidence among elderly individuals.

The TP53 codon 72 polymorphism was not found to be associated with the clinical characteristics of pancreatic cancer, such as tumor location, tumor size, TNM stage, carbohydrate antigen 19-9 (CA19-9) level, presence of diabetes, surgery or past history or familial history of cancer among the cases.

Our results have several limitations. First, our study had a hospital-based case-control design with healthy controls recruited from two locations: the Saitama and Okayama prefectures. The Saitama prefecture is in eastern Japan near Tokyo, while Okayama is in western Japan. However, the Japanese are almost racially homogenous, and genotype distribution in both populations was in Hardy-Weinberg equilibrium (Arg/Arg, Arg/Pro and Pro/Pro were found to be 44, 48 and $9 \%$ in the Saitama controls, and 44,44 and $11 \%$ in the Okayama controls, respectively). The difference between the two sources was not statistically significant $(\mathrm{P}=0.633)$. Second, we could not adjust for other confounding factors, such as diabetes, obesity, and the activity of tobacco and alcohol metabolizing enzymes, including cytochrome P450, ALDH, alcohol dehydrogenase $1 \mathrm{~B}$ and alcohol dehydrogenase 1C. Third, there is a possibility of a false-positive result due to the small sample size, particularly in the subgroup analyses.

Despite these limitations, the results provide insights into the identification of a group at high risk of developing pancreatic cancer. This study may contribute to the development of early detection strategy and the prevention of pancreatic cancer.

In conclusion, we found that the TP53 Pro/Pro genotype had a profound effect on pancreatic cancer risk among males, in particular heavy smokers and excessive alcohol drinkers. Since our study scale was small, replication studies with more samples are warranted.

\section{Acknowledgements}

We acknowledge Dr Y. Kusaka of Kusaka Hospital (Bizen Okakaya) for the great help, and Dr J.B. Cologne for the advice on bio-statistical analyses. This study was supported by a grant from the Ministry of Education, Culture, Sports, Science and Technology of Japan (20014013).

\section{References}

1. Foundation for Promotion of Cancer Research: Cancer Statistics in Japan, 2008

2. Jemal A, Siegel R, Ward E, Hao Y, Xu J, Murray T and Thun MJ: Cancer Statistics, 2008. CA Cancer J Clin 58: 71-96, 2008.

3. Ferlay J, Autier P, Boniol M, Heanue M, Colombet M and Boyle P: Estimates of the cancer incidence and mortality in Europe in 2006. Ann Oncol 18: 581-592, 2007.

4. Pierantoni C, Pagliacci A, Scartozzi M, Berardi R, Bianconi M and Cascinu S: Pancreatic cancer: progress in cancer therapy. Crit Rev Oncol Hematol 67: 27-38, 2008.

5. Li D, Xie K, Wolff R and Abbruzzese JL: Pancreatic cancer. Lancet 363: 1049-1057, 2004.

6. Gold EB: Epidemiology of and risk factors for pancreatic cancer. Surg Clin North Am 75: 819-843, 1995.

7. Qiu D, Kurosawa M, Lin Y, et al: Overview of the epidemiology of pancreatic cancer focusing on the JACC Study. J Epidemiol 15: S157-S167, 2005.

8. Lowenfels AB, Maisonneuve P and Whitcomb DC: Risk factors for cancer in hereditary pancreatitis. International Hereditary Pancreatitis Study Group. Med Clin North Am 84: 565-573, 2000.

9. Lin Y, Tamakoshi A, Kawamura T, et al: An epidemiological overview of environmental and genetic risk factors of pancreatic cancer. Asian Pac J Cancer Prev 2: 271-280, 2001.

10. Lynch SM, Vrieling A, Lubin JH, et al: Cigarette smoking and pancreatic cancer: a pooled analysis from the Pancreatic Cancer Cohort Consortium. Am J Epidemiol 170: 403-413, 2009.

11. Partanen TJ, Vainio HU, Ojajarvi IA and Kauppinen TP: Pancreas cancer, tobacco smoking and consumption of alcoholic beverages: a case-control study. Cancer Lett 116: 27-32, 1997.

12. Inoue M, Noda M, Kurahashi N, et al: Impact of metabolic factors on subsequent cancer risk: results from a large-scale population-based cohort study in Japan. Eur J Cancer Prev 18: 240-247, 2009.

13. Michaud DS, Giovannucci E, Willett WC, Colditz GA, Stampfer MJ and Fuchs CS: Physical activity, obesity, height, and the risk of pancreatic cancer. JAMA 286: 921-929, 2001.

14. Everhart J and Wright D: Diabetes mellitus as a risk factor for pancreatic cancer. A meta-analysis. JAMA 273: 1605-1609, 1995.

15. Huxley R, Ansary-Moghaddam A, Berrington de Gonzalez A, Barzi F and Woodward M: Type-II diabetes and pancreatic cancer: a meta-analysis of 36 studies. Br J Cancer 92: 2076-2083, 2005.

16. Ghadirian P, Baillargeon J, Simard A and Perret C: Food habits and pancreatic cancer: a case-control study of the Francophone community in Montreal, Canada. Cancer Epidemiol Biomarkers Prev 4: 895-899, 1995.

17. Larsson SC, Hakansson N, Giovannucci E and Wolk A: Folate intake and pancreatic cancer incidence: a prospective study of Swedish women and men. J Natl Cancer Inst 98: 407-413, 2006.

18. Bansal P and Sonnenberg A: Pancreatitis is a risk factor for pancreatic cancer. Gastroenterology 109: 247-251, 1995.

19. Lowenfels AB, Maisonneuve P, Cavallini G, et al: Pancreatitis and the risk of pancreatic cancer. International Pancreatitis Study Group. N Engl J Med 328: 1433-1437, 1993.

20. Ghadirian P, Lynch HT and Krewski D: Epidemiology of pancreatic cancer: an overview. Cancer Detect Prev 27: 87-93, 2003

21. Landi S: Genetic predisposition and environmental risk factors to pancreatic cancer: a review of the literature. Mutat Res 681: 299-307, 2009.

22. Ockenga J, Vogel A, Teich N, Keim V, Manns MP and Strassburg CP: UDP glucuronosyltransferase (UGT1A7) gene polymorphisms increase the risk of chronic pancreatitis and pancreatic cancer. Gastroenterology 124: 1802-1808, 2003.

23. Li D, Jiao L, Li Y, et al: Polymorphisms of cytochrome P4501A2 and $\mathrm{N}$-acetyltransferase genes, smoking, and risk of pancreatic cancer. Carcinogenesis 27: 103-111, 2006.

24. Duell EJ, Holly EA, Bracci PM, Wiencke JK and Kelsey KT: A population-based study of the Arg399Gln polymorphism in $\mathrm{X}$-ray repair cross- complementing group 1 (XRCC1) and risk of pancreatic adenocarcinoma. Cancer Res 62: 4630-4636, 2002.

25. Jiao L, Hassan MM, Bondy ML, Wolff RA, Evans DB, Abbruzzese JL and Li D: XRCC2 and XRCC3 gene polymorphism and risk of pancreatic cancer. Am J Gastroenterol 103: 360-367, 2008 . 
26. Li D, Ahmed M, Li Y, et al: 5,10-Methylenetetrahydrofolate reductase polymorphisms and the risk of pancreatic cancer. Cancer Epidemiol Biomarkers Prev 14: 1470-1476, 2005.

27. Larsson SC, Giovannucci E and Wolk A: Folate intake, MTHFR polymorphisms, and risk of esophageal, gastric, and pancreatic cancer: a meta-analysis. Gastroenterology 131: 1271-1283, 2006.

28. Ohnami S, Sato Y, Yoshimura K, et al: His595Tyr polymorphism in the methionine synthase reductase (MTRR) gene is associated with pancreatic cancer risk. Gastroenterology 135: 477-488, 2008.

29. Zhao D, Xu D, Zhang X, et al: Interaction of cyclooxygenase-2 variants and smoking in pancreatic cancer: a possible role of nucleophosmin. Gastroenterology 136: 1659-1668, 2009.

30. Popanda O, Edler L, Waas P, et al: Elevated risk of squamouscell carcinoma of the lung in heavy smokers carrying the variant alleles of the TP53 Arg72Pro and p21 Ser31 Arg polymorphisms. Lung Cancer 55: 25-34, 2007.

31. Fernandez-Rubio A, Lopez-Cima MF, Gonzalez-Arriaga P, Garcia-Castro L, Pascual T, Marron MG and Tardon A: The TP53 Arg72Pro polymorphism and lung cancer risk in a population of Northern Spain. Lung Cancer 61: 309-316, 2008.

32. Singh V, Rastogi N, Mathur N, Singh K and Singh MP: Association of polymorphism in MDM-2 and p53 genes with breast cancer risk in Indian women. Ann Epidemiol 18: 48-57, 2008.

33. Cao Z, Song JH, Park YK, Maeng EJ, Nam SW, Lee JY and Park WS: The p53 codon 72 polymorphism and susceptibility to colorectal cancer in Korean patients. Neoplasma 56: 114-118, 2009.

34. Jones JS, Chi X, Gu X, Lynch PM, Amos CI and Frazier ML: p53 polymorphism and age of onset of hereditary nonpolyposis colorectal cancer in a Caucasian population. Clin Cancer Res 10: 5845-5849, 2004.

35. Yang M, Guo Y, Zhang X, et al: Interaction of P53 Arg72Pro and MDM2 T309G polymorphisms and their associations with risk of gastric cardia cancer. Carcinogenesis 28: 1996-2001, 2007.

36. Zhu ZZ, Cong WM, Liu SF, Dong H, Zhu GS and Wu MC: Homozygosity for Pro of p53 Arg72Pro as a potential risk factor for hepatocellular carcinoma in Chinese population. World J Gastroenterol 11: 289-292, 2005

37. Parhar P, Ezer R, Shao Y, Allen JC, Miller DC and Newcomb EW: Possible association of p53 codon 72 polymorphism with susceptibility to adult and pediatric high-grade astrocytomas. Mol Brain Res 137: 98-103, 2005.

38. Naccarati A, Pardini B, Polakova V, et al: Genotype and haplotype analysis of TP53 gene and the risk of pancreatic cancer: an association study in the Czech Republic. Carcinogenesis 31: 666-670, 2010
39. Kanzaki H, Ouchida M, Hanafusa H, et al: Single nucleotide polymorphism in the RAD18 gene and risk of colorectal cancer in the Japanese population. Oncol Rep 18: 1171-1175, 2007.

40. Imyanitov EN: Gene polymorphisms, apoptotic capacity and cancer risk. Hum Genet 125: 239-246, 2009.

41. Pim D and Banks L: Polymorphic variants at codon 72 exert different effects on cell cycle progression. Int J Cancer 108: 196-199, 2004

42. Dumont P, Leu JI, Della Pietra AC III, George DL and Murphy M: The codon 72 polymorphic variants of p53 have markedly different apoptotic potential. Nat Genet 33: 357-365, 2003.

43. Bergamaschi D, Samuels Y, Sullivan A, et al: iASPP preferentially binds 553 proline-rich region and modulates apoptotic function of codon 72-polymorphic p53. Nat Genet 38: 1133-1141, 2006.

44. Lin Y, Tamakoshi A, Kawamura T, Inaba Y, Kikuchi S, Motohashi Y and Kurosawa M: JACC Study Group: a prospective cohort study of cigarette smoking and pancreatic cancer in Japan. Cancer Causes Control 13: 249-254, 2002.

45. Go VL, Gukovskaya A and Pandol SJ: Alcohol and pancreatic cancer. Alcohol 35: 205-211, 2005.

46. Inoue M and Tsugane S: JPHC Study Group: Impact of alcohol drinking on total cancer risk: data from a large-scale populationbased cohort study in Japan. Br J Cancer 92: 182-187, 2005.

47. Malats N, Porta M, Corominas JM, Piñol JL, Rifà J and Real FX Ki-ras mutations in exocrine pancreatic cancer: association with clinico-pathological characteristics and with tobacco and alcohol consumption. PANK-ras I Project Investigators. Int J Cancer 70: 661-667, 1997.

48. Suzuki H, Morris JS, Li Y, et al: Interaction of the cytochrome P4501A2, SULT1A1 and NAT gene polymorphisms with smoking and dietary mutagen intake in modification of the risk of pancreatic cancer. Carcinogenesis 29: 1184-1191, 2008.

49. El Hallani S, Ducray F, Idbaih A, et al: TP53 codon 72 polymorphism is associated with age at onset of glioblastoma. Neurology 72: 332-336, 2009.

50. Yoon YJ, Chang HY, Ahn SH, et al: MDM2 and p53 polymorphisms are associated with the development of hepatocellular carcinoma in patients with chronic hepatitis B virus infection. Carcinogenesis 29: 1192-1196, 2008.

51. Shen H, Zheng Y, Sturgis EM, Spitz MR and Wei Q: P53 codon 72 polymorphism and risk of squamous cell carcinoma of the head and neck: a case-control study. Cancer Lett 183: 123-130, 2002.

52. Ørsted DD, Bojesen SE, Tybjaerg-Hansen A and Nordestgaard BG: Tumor suppressor p53 Arg72Pro polymorphism and longevity, cancer survival, and risk of cancer in the general population. J Exp Med 204: 1295-1301, 2007. 